Am J Psychiatry Vol. 162(6):1142-1148 (2005)

ISSN: (print 0002-953X)(online 1535-7228)

This is a peer reviewed pre-print version of the following article: Risperidone for the Core Symptom Domains of Autism: Results From the Study by the Autism Network of the Research Units on Pediatric Psychopharmacology, which has been published in final form at:

http://www.appi.org

http://www.appi.org/SearchCenter/Pages/Journal.aspx?ItemId=AJP

http://ajp.psychiatryonline.org/article.aspx?articleid=177599

(C) 2005 American Psychiatric Publishing, Inc.

\title{
Risperidone for the Core Symptom Domains of Autism: Results From the Study by the Autism Network of the Research Units on Pediatric Psychopharmacology
}

\author{
Christopher J. McDougle, M.D., Lawrence Scahill, M.S.N., Ph.D., Michael G. Aman, \\ Ph.D., James T. McCracken, M.D., Elaine Tierney, M.D., Mark Davies, M.P.H., L. \\ Eugene Arnold, M.D., David J. Posey, M.D., Andrès Martin, M.D., M.P.H., Jaswinder \\ K. Ghuman, M.D., Bhavik Shah, M.D., Shirley Z. Chuang, M.S., Naomi B. Swiezy, \\ Ph.D., Nilda M. Gonzalez, M.D., Jill Hollway, B.A., Kathleen Koenig, M.S.N., James J. \\ McGough, M.D., Louise Ritz, M.B.A., Benedetto Vitiello, M.D.
}

Abstract

Objective: Risperidone has been found efficacious for decreasing severe tantrums, aggression, and self-injurious behavior in children and adolescents with autistic disorder (autism). The authors report on whether risperidone improves the core symptoms of autism, social and communication impairment and repetitive and stereotyped behavior.

Method: The database from an 8-week double-blind, placebo-controlled trial $(\mathrm{N}=101)$ and 16-week open-label continuation study $(\mathrm{N}=63)$ of risperidone for children and adolescents with autism was used to test for drug effects on secondary outcome measures: scores on the Ritvo-Freeman Real Life Rating Scale, the Children's Yale-Brown Obsessive Compulsive Scale, and the maladaptive behavior domain of the Vineland Adaptive Behavior Scales.

Results: Compared to placebo, risperidone led to a significantly greater reduction in the overall score on the Ritvo-Freeman Real Life Rating Scale, as well as the scores on the subscales for sensory motor behaviors (subscale I), affectual reactions (subscale III), and sensory responses (subscale IV). No statistically significant difference was observed, however, on the subscale for social relatedness (subscale II) or language (subscale V). Risperidone also resulted in significantly greater reductions in scores on the Children's Yale-Brown Obsessive Compulsive Scale and Vineland maladaptive behavior domain. This pattern of treatment response was maintained for 6 months.

Conclusions: Risperidone led to significant improvements in the restricted, repetitive, and stereotyped patterns of behavior, interests, and activities of autistic children but did not significantly change their deficit in social interaction and communication. Further research is necessary to develop effective treatments for the core social and communicative impairments of autism.

Autistic disorder (autism) is a pervasive developmental disorder whose core symptoms are a qualitative impairment in social interaction and communication and restricted repetitive and stereotyped patterns of behavior, interests, and activities. Children with autism frequently have associated behavioral disturbances, such as severe tantrums, aggression, and self-injury, which can profoundly impair their functioning. In the initial study by the Autism Network of the Research Units on Pediatric Psychopharmacology, treatment with the atypical antipsychotic risperidone resulted in a significant improvement of these associated maladaptive behaviors (1). Less clear, however, is whether risperidone can also improve the core symptoms of autism. This article describes an attempt to address this clinically important issue. The rationale for choosing 
risperidone as the initial drug of investigation (2), the development of the assessment strategy (3), and the design and other methodological challenges of the study (4) are described elsewhere.

In the initial 8-week multisite randomized, double-blind, placebo-controlled trial, the primary outcome measures were the irritability subscale of the Aberrant Behavior Checklist (5) and the Clinical Global Impression (CGI) improvement scale (6). A positive responder was defined as any child who showed a $25 \%$ reduction on the irritability subscale and who was rated as much improved or very much improved (i.e., 2 or 1, respectively) on the CGI improvement scale. According to these treatment response criteria, 34 (69\%) of the 49 children randomly assigned to risperidone were categorized as responders versus six (12\%) of the 52 children given placebo.

At the end of the 8-week controlled trial, subjects who were initially assigned to placebo who did not respond were eligible to receive an 8-week trial of open-label risperidone. Subjects who showed a positive response to risperidone in either the 8-week controlled study or the 8-week open-label trial were offered enrollment in a 16-week open-label continuation phase (7). This phase of the study allowed for a determination of the maintenance of improvement in the symptoms of tantrums, aggression, and self-injury over an extended period of time.

In addition to the primary outcome variables, the study incorporated a number of secondary outcome measures, including the Ritvo-Freeman Real Life Rating Scale (8), the Children's Yale-Brown Obsessive Compulsive Scale (9), and the maladaptive behavior domain of the Vineland Adaptive Behavior Scales (10). These scales were included in order to determine the effects of risperidone on target symptom domains beyond those of tantrums, aggression, and self-injury.

The Ritvo-Freeman Real Life Rating Scale includes subscales that measure "social relationship to people" and "language." The items in these subscales cover the first two DSM-IV diagnostic domains for autism: qualitative impairment in social interaction and communication, respectively. The compulsion scale of the Children's Yale-Brown Obsessive Compulsive Scale is designed to measure repetitive behavior. This scale captures symptoms similar to those defined by the third DSM-IV diagnostic criterion for autism, restricted repetitive and stereotyped patterns of behavior, interests, and activities. Thus, these secondary measures allowed for an exploratory analysis of the effects of risperidone on the core symptom domains of autism.

The original report (1) summarized the results on the primary outcome instruments, and a secondary methodological report provided results on parent-chosen, clinician-rated target symptoms (11). In the current analysis, using the findings on all remaining outcome measures, we tested the hypothesis that risperidone is superior to placebo for reducing repetitive behavior and that it improves measures of social relatedness and impaired communication. We also evaluated whether any improvements in these domains were maintained over the 16-week open-label continuation treatment phase.

\section{Method}

\section{Participants}

The study sites included Indiana University, the Kennedy Krieger Institute at Johns Hopkins University, Ohio State University, the University of California at Los Angeles, and Yale University. The protocol was approved by the institutional review board at each site, and written informed consent was obtained from a parent or legal guardian before enrollment.

The details of the study participants are described elsewhere $(1,7)$. Briefly, they were 101 children and adolescents between the ages of 5 and 17 years (mean age=8.8 years, SD=2.7); 
82\% were male. They met the DSM-IV criteria for a diagnosis of autistic disorder, which was corroborated by the Autism Diagnostic Interview-Revised (12), and they had impairing behavioral symptoms, such as severe tantrums, aggression, or self-injurious behavior.

These subjects were randomly assigned to 8 weeks of risperidone (dose range $=0.5-3.5$ $\mathrm{mg} /$ day, mean=1.8 $\mathrm{mg} /$ day, $\mathrm{SD}=0.7$ ) or placebo in a double-blind trial. On the primary outcome measures, the Aberrant Behavior Checklist irritability subscale and the CGI improvement scale, risperidone was superior to placebo $(\mathrm{p}<0.001)(1)$. Thirty-four $(69 \%)$ of 49 subjects showed a positive response to risperidone during the 8-week double-blind study, and 29 (63\%) of 46 subjects responded to risperidone in the 8-week open-label trial for the nonresponders in the placebo group. Thus, a total of 63 subjects entered the 16 -week continuation phase. At the beginning of the extension phase, there were no differences between these two groups in the scores on the irritability subscale of the Aberrant Behavior Checklist or in the distribution of CGI severity scores. Therefore, the two groups were combined in the efficacy analysis. A detailed description of the baseline characteristics of this group are described elsewhere (7). Following the 16-week open-label continuation phase, $83 \%$ of the subjects continued to be rated as much improved or very much improved ( 2 or 1 on the CGI improvement scale). The mean daily dose of risperidone for the subjects beginning the 16-week continuation phase was $2.0 \mathrm{mg}(\mathrm{SD}=1.2)$. Over the course of the 16-week open-label treatment, there was a modest increase (6\%) to a final mean daily dose of risperidone of $2.1 \mathrm{mg}(\mathrm{SD}=0.8)$.

\section{Ritvo-Freeman Real Life Rating Scale}

This scale was developed to evaluate the effects of treatments on symptomatic behaviors in patients with the syndrome of autism (8). It was designed as a direct observation measure that could be applicable to patients in their natural settings. Direct observation is one way of compensating for a patient's limited ability to communicate (3). The Ritvo-Freeman Real Life Rating Scale has been used to measure change in behavioral symptoms in controlled drug treatment studies involving children (13), as well as adults $(14,15)$, with autism. The studies with adults, however, involved only one investigative site and a single rater. For the current study, even with extensive and repeated training and standardization of procedures for the 30-minute observation period, we were unable to attain acceptable reliability across the five study sites for direct observation. We next considered videotaping the 30-minute observation protocol for later coding/rating by reliable raters. However, the validity of videotaping live examinations as a way of recording a representative sample of the subject's behavior seemed questionable (16). Therefore, we modified the Ritvo-Freeman Real Life Rating Scale to convert it from an observational measure to a parent rating scale. In the adapted version, the original scales were retained and the items were rephrased to allow parents to rate each of the 47 items from 0 to 3 as described in the following.

Like the original instrument, our modified Ritvo-Freeman Real Life Rating Scale included subscales for assessing sensory motor behaviors (e.g., hand flapping, rocking, pacing) (subscale I), social relatedness (e.g., appropriate responses to interaction attempts, initiation of appropriate physical interactions) (subscale II), affectual reactions (e.g., abrupt changes in affect, crying, temper outbursts) (subscale III), sensory responses (e.g., being agitated by noises, rubbing surfaces, sniffing self or objects) (subscale IV), and language (e.g., communicative use of language, initiation of appropriate verbal communication) (subscale V). Each of the five subscales contained a number of individual items that were scored on a 4-point scale: 0 indicated "never," 1 signified “infrequently (occasionally)," 2 indicated "frequently (daily)," and 3 represented "almost always." The average of the mean values for each of the five subscale scores 
was determined to yield an overall score. The score on the Ritvo-Freeman Real Life Rating Scale increases as the number and frequency of symptoms of autism increase. A mathematical sign correction to subtract normal behavior is necessary on subscales II, IV, and V; this could result in negative values on some subscales. 


\begin{tabular}{|c|c|c|c|c|c|c|c|c|c|c|}
\hline & \multirow{4}{*}{$\begin{array}{l}\text { Measure From Ritvo-Freeman } \\
\text { Real Life Rating Scale }\end{array}$} & \multirow{2}{*}{\multicolumn{6}{|c|}{ Score in Placebo-Controlled Trial $(\mathrm{N}=101)$}} & \multicolumn{3}{|c|}{ Results of Placebo-Controlled } \\
\hline & & & & & & & & \multirow{3}{*}{$\begin{array}{c}\text { End-of-Stu } \\
\text { dy Effect } \\
\text { Size } \\
\text { (Cohen's d) }\end{array}$} & \multirow{2}{*}{\multicolumn{2}{|c|}{$\begin{array}{c}\text { Interaction of } \\
\text { Treatment With } \\
\text { TIme }\end{array}$}} \\
\hline & & \multicolumn{2}{|c|}{ Baseline } & \multicolumn{2}{|c|}{ Week 4} & \multicolumn{2}{|c|}{ Week 8} & & & \\
\hline & & Mean & SD & Mean & SD & Mean & SD & & $\mathrm{F}(\mathrm{df}=1,87)$ & $\mathrm{p}$ \\
\hline \multicolumn{8}{|c|}{ Subscale I: sensory motor behaviors } & 0.45 & 10.8 & 0.002 \\
\hline \multicolumn{2}{|c|}{ Risperidone } & 1.00 & 0.52 & 0.65 & 0.43 & 0.59 & 0.42 & & & \\
\hline \multicolumn{2}{|c|}{ Placebo } & 0.93 & 0.58 & 0.83 & 0.47 & 0.91 & 0.60 & & & \\
\hline \multicolumn{2}{|c|}{ Risperidone } & 0.60 & 0.43 & 0.20 & 0.43 & 0.15 & 0.42 & & & \\
\hline \multicolumn{2}{|c|}{ Placebo } & 0.72 & 0.43 & 0.47 & 0.51 & 0.46 & 0.52 & & & \\
\hline \multicolumn{2}{|c|}{ Subscale III: affectual reactions } & & & & & & & 1.10 & 15.4 & $<0.001$ \\
\hline \multicolumn{2}{|c|}{ Risperidone } & 1.68 & 0.64 & 1.00 & 0.67 & 0.88 & 0.56 & & & \\
\hline \multicolumn{2}{|c|}{ Placebo } & 1.84 & 0.64 & 1.64 & 0.64 & 1.60 & 0.71 & & & \\
\hline \multicolumn{2}{|c|}{ Subscale V: language } & & & & & & & 0.81 & - & n.s. \\
\hline \multicolumn{2}{|c|}{ Risperidone } & 0.28 & 0.38 & 0.15 & 0.31 & 0.03 & 0.29 & & & \\
\hline \multicolumn{2}{|c|}{ Placebo } & 0.46 & 0.42 & 0.30 & 0.39 & 0.34 & 0.41 & & & \\
\hline \multicolumn{2}{|l|}{ Overall } & & & & & & & 1.08 & 15.3 & $<0.001$ \\
\hline \multicolumn{2}{|c|}{ Risperidone } & 0.94 & 0.36 & 0.54 & 0.36 & 0.45 & 0.31 & & & \\
\hline \multicolumn{2}{|c|}{ Placebo } & 1.03 & 0.37 & 0.84 & 0.39 & 0.88 & 0.40 & & & \\
\hline
\end{tabular}

TABLE 1. Scores on the Ritvo-Freeman Real Life Rating Scale of Children and Adolescents With Autism in a Placebo-Controlled Risperidone Trial and Open-Label Continuation Study 
The scale was administered at baseline and at the end of weeks 4 and 8 during the controlled trial and monthly thereafter for subjects who entered the 16-week open-label continuation phase of the study (i.e., 12, 16, 20, and 24 weeks after baseline). The parent or primary caregiver was asked to consider the child's behavior over the past month.

\section{Children's Yale-Brown Obsessive Compulsive Scale}

This scale is a reliable and valid semistructured clinician-rated measure of obsessive-compulsive symptom severity in children and adolescents with obsessive-compulsive disorder (OCD) (9). The Children's Yale-Brown Obsessive Compulsive Scale is a modified version of the Yale-Brown Obsessive Compulsive Scale, which was developed for adults with OCD (17, 18). Like the adult version, the scale for children is a 10 -item clinician-rated, semi-structured instrument designed to assess the severity of OCD symptoms over the previous week. The overall structure, anchor points, and scoring of the original instrument were retained in the children's version, but the wording of the probe questions was modified to make them more developmentally appropriate for children and adolescents.

The severity of the endorsed obsessions is rated on five items: time spent, interference, associated distress, degree of resistance against the thoughts, and degree of control over obsessive thoughts. Each of these five items is rated on a 5-point ordinal scale: 0 indicates "none”; 1 , “mild”; 2 , “moderate”; 3 , "severe”; and 4, "extreme.” The obsessions severity score is obtained by adding the scores for items 1 through 5 (range $=0$ to 20). There are five comparable severity items for compulsions (items 6 through 10), which are also scored from 0 to 4 . The compulsion severity score is obtained by adding the scores on items 6 through 10 (range $=0$ to 20). Summing the scores for all 10 items yields the total score on the Children's Yale-Brown Obsessive Compulsive Scale (range $=0$ to 40 ). Because many children with autism have limited cognitive and verbal communication abilities, we used only the compulsion subscale of the Children's Yale-Brown Obsessive Compulsive Scale (range=0-20). These cognitive and communication impairments may also limit the subject's ability to describe his or her subjective experience concerning resistance and degree of control over repetitive behavior. For these items, we relied on the parent as the primary informant. Children with OCD typically describe distress associated with the performance of their unwanted rituals (19). By contrast, children and adults with autism often engage in self-stimulating or self-soothing stereotypic behaviors and do not appear distressed during the performance of repetitive behavior $(20,21)$. Because of these observations, the modified Children's Yale-Brown Obsessive Compulsive Scale did not require the subject's recognition that the behavior is excessive. To capture stereotypic behaviors, the scale's symptom checklist was expanded to include repetitive behaviors associated with autism, such as spinning objects, staring, twirling, and repeating words and phrases.

Reliability was established through multiple training sessions and co-rating of videotaped interviews. Each clinical rater had to achieve a criterion of $\pm 15 \%$ of the gold standard established by an experienced rater (L.S.). For example, if the gold standard rating total for a videotaped interview was 14, the other raters had to rate the same tape between 12 and 16 to qualify as a rater; if the gold standard was 10, they had to rate the tape between 9 and 11. Anyone who did not meet this criterion on four tapes underwent further training and rated additional tapes until qualified. The Children's Yale-Brown Obsessive Compulsive Scale was administered by a blinded clinician at baseline and at the end of 2, 4, 6, and 8 weeks of the controlled drug study. This measure was also administered on a monthly basis during the 16-week open-label continuation phase (i.e., 12, 16, 20, and 24 weeks after baseline). The scores determined by the clinical rater were based on the information provided by the subject's parent or primary caregiver during the 
interview regarding his or her child's repetitive behavior over the interval since the last assessment.

\section{Maladaptive Behavior Domain of Vineland Adaptive Behavior Scales}

The maladaptive behavior domain of the Vineland Adaptive Behavior Scales (10) was completed by trained clinicians by means of a parent interview. The maladaptive behavior domain is divided into two subscales: part 1 consists of 27 items, and part 2 consists of nine items. Each item is scored on a 3-point scale where 0 indicates "no, never," 1 indicates "sometimes or partially," and 2 signifies "yes, usually.” Thus, the range of scores for part 1 was 0 to 54, the range for part 2 was 0 to 18, and the range for the total score was 0 to 72 . Part 1 includes mood- and anxiety-related along with hyperactivity, lying, cheating, bed-wetting, and others. Part 2 contains more severe symptoms, including psychosis, self-injury, and property destruction. These subscales have previously been shown to be sensitive to change with medication in pharmacological studies involving subjects with autism $(14,22)$. Ratings on this secondary outcome measure were obtained by interview at baseline, at week 8 of the placebo-controlled phase, and at the end of the 16-week open-label continuation phase of the study (i.e., 24 weeks after baseline).

\begin{tabular}{ccccccccc}
\hline \multicolumn{1}{c}{ Score in Open-Label Continuation Study } \\
\hline \multicolumn{1}{c}{ Week 12 } & \multicolumn{1}{c}{ Week 16 } & \multicolumn{5}{c}{ Week 20 } & \multicolumn{3}{c}{ Week 24 } \\
Mean & SD & Mean & SD & Mean & SD & Mean & SD \\
\hline 0.59 & 0.43 & 0.54 & 0.42 & 0.54 & 0.49 & 0.60 & 0.49 \\
& & & & & & & \\
0.06 & 0.42 & 0.04 & 0.45 & 0.02 & 0.46 & 0.00 & 0.42 \\
0.89 & 0.62 & 0.81 & 0.44 & 0.87 & 0.60 & 0.78 & 0.58 \\
0.55 & 0.40 & 0.48 & 0.39 & 0.50 & 0.42 & 0.45 & 0.37 \\
0.07 & 0.34 & 0.05 & 0.38 & 0.06 & 0.39 & 0.10 & 0.36 \\
0.43 & 0.34 & 0.38 & 0.31 & 0.40 & 0.39 & 0.39 & 0.35 \\
& & & & & & & \\
\hline
\end{tabular}

\section{Statistical Analysis}

The data were analyzed according to the intent-to-treat principle. The statistical tests were two-tailed, and p values of 0.05 or less were considered to indicate statistical significance. Bonferroni correction for multiple tests was not done because the different instruments measured different domains of functioning. For the 8-week controlled trial, the monthly and biweekly scores on the Ritvo-Freeman Real Life Rating Scale and the Children's Yale-Brown Obsessive Compulsive Scale, respectively, were analyzed with the use of mixed-effects linear models in which the study group and site were the fixed effects and the outcome and time were the random effects (23). The mixed-effects approach makes full use of available data and allowed us to combine subject-specific scores on the Ritvo-Freeman Real Life Rating Scale and Children's Yale-Brown Obsessive Compulsive Scale in order to estimate the slope of the regression line for each group over time. A strong downward trend in scores in the risperidone group, as compared with the placebo group, would indicate a statistically significant interaction between treatment 
and time. Site-by-treatment interactions that were not significant were removed from the final model. The parameters of the mixed-effects model were estimated with the use of SAS Proc Mixed software (24). Because the Vineland maladaptive behavior domain scales had insufficient data points for the mixed-effects model, analysis of covariance was used to compare groups during the placebo-controlled phase.

For the 16-week open-label continuation phase, the monthly scores on the Ritvo-Freeman Real Life Rating Scale and the Children's Yale-Brown Obsessive Compulsive Scale were analyzed with mixed-effects linear regression models in which time, site, and the site-by-time interaction were the fixed effects. The average slope of the regression line was calculated for each individual across time. Paired t tests of scores on the Vineland along with hyperactivity, lying, cheating, bed-wetting, and others. Part 2 maladaptive behavior domain scales were used to compare the values at the beginning of the 16-week open-label continuation phase with the scores at the end (week 24).

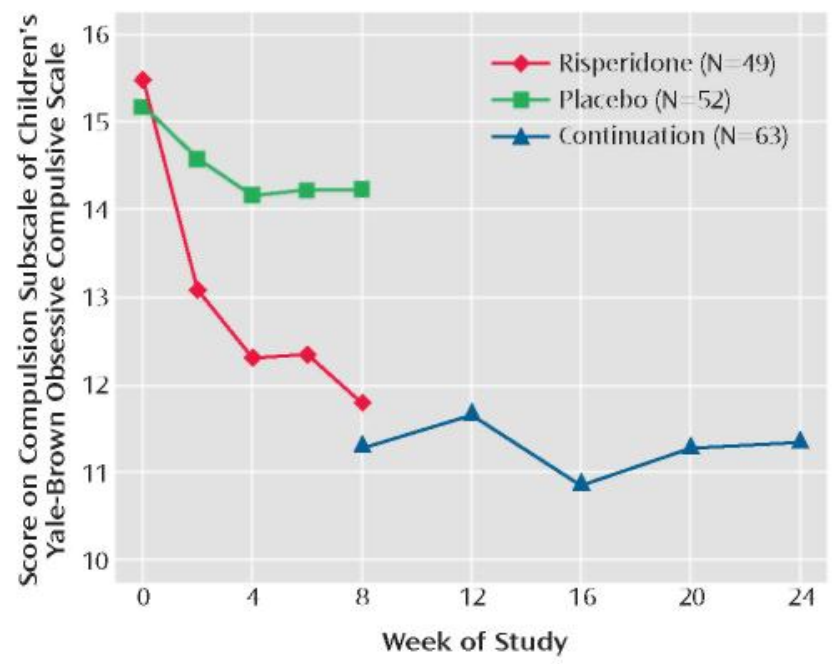

FIGURE 1. Scores for Compulsions on the Children's Yale-Brown Obsessive Compulsive Scale of Children and Adolescents in a Placebo-Controlled Risperidone Trial and Open-Label Continuation Study

\section{Results}

\section{Ritvo-Freeman Real Life Rating Scale}

Risperidone significantly decreased the overall score on the Ritvo-Freeman scale and the scores on the subscales for sensory motor behaviors (subscale I), affectual reactions (subscale III), and sensory responses (subscale IV), but it had no statistically significant effect on the score on the subscale for social relatedness (subscale II) or language (subscale V). Table 1 shows the mean scores at baseline, the end of week 4, and the end of week 8 , as well as the effect size, for each of the five subscales and the overall Ritvo-Freeman Real Life Rating Scale in each study group during the 8-week controlled phase of the study. The scores are also shown for the monthly measurements in the 16-week open-label continuation phase. There was no significant change in any of these measures over the course of the continuation phase.

\section{Children's Yale-Brown Obsessive Compulsive Scale}

Figure 1 shows the mean scores at baseline and at the end of weeks 2, 4, 6, and 8 on the modified compulsion scale of the Children's Yale-Brown Obsessive Compulsive Scale for each study group during the 8-week controlled phase of the study. The mean score went from 15.51 
$(\mathrm{SD}=2.73)$ to $11.65(\mathrm{SD}=4.02)$ in the risperidone group compared to $15.18(\mathrm{SD}=3.88)$ to 14.21 $(\mathrm{SD}=4.81)$ in the placebo group. There was a significant interaction between study group and time $(\mathrm{F}=8.21, \mathrm{df}=1,243, \mathrm{p}=0.005)$; the effect size (Cohen's $\mathrm{d}$ ) was 0.55 . The mean values are also shown for the 16-week open-label continuation phase. There was no significant change in this measure during the continuation. 


\begin{tabular}{|c|c|c|c|c|c|c|c|c|c|}
\hline \multirow{4}{*}{$\begin{array}{l}\text { Measure From } \\
\text { Maladaptive Behavior } \\
\text { Domain of Vineland } \\
\text { Adaptive Behavior Scales }\end{array}$} & \multirow{2}{*}{\multicolumn{4}{|c|}{$\begin{array}{l}\text { Score in Placebo-Controlled Trial } \\
\qquad(\mathrm{N}=101)\end{array}$}} & \multicolumn{3}{|c|}{ Results of Placebo-Controlled Trial } & \multirow{3}{*}{\multicolumn{2}{|c|}{$\begin{array}{l}\text { Score at Week 24: End of Open- } \\
\text { Label Continuation Study } \\
\qquad(\mathrm{N}=63)\end{array}$}} \\
\hline & & & & & \multirow{3}{*}{$\begin{array}{l}\text { End-of-Study } \\
\text { Effect Size } \\
\text { (Cohen’s d) }\end{array}$} & \multirow{2}{*}{\multicolumn{2}{|c|}{$\begin{array}{c}\text { Interaction of Treatment } \\
\text { With Time }\end{array}$}} & & \\
\hline & \multicolumn{2}{|c|}{ Baseline } & \multicolumn{2}{|c|}{ Week 8} & & & & & \\
\hline & Mean & SD & Mean & SD & & $\mathrm{F}(\mathrm{df}=1,84)$ & $\mathrm{p}$ & Mean & SD \\
\hline Part 1 & & & & & 1.17 & 34.2 & $<0.001$ & & \\
\hline Risperidone & 24.89 & 6.91 & 14.89 & 5.93 & & & & 16.55 & 6.87 \\
\hline Placebo & 25.22 & 5.72 & 22.97 & 5.99 & & & & & \\
\hline Part 2 & & & & & 0.49 & 6.7 & 0.02 & & \\
\hline Risperidone & 8.37 & 2.59 & 5.45 & 3.25 & & & & 5.04 & 3.20 \\
\hline Placebo & 8.29 & 3.66 & 7.30 & 3.45 & & & & & \\
\hline Total & & & & & 1.03 & 26.6 & $<0.001$ & & \\
\hline Risperidone & 33.26 & 8.38 & 20.34 & 7.93 & & & & 21.60 & 9.50 \\
\hline Placebo & 33.51 & 8.29 & 30.27 & 8.87 & & & & & \\
\hline
\end{tabular}

TABLE 2. Scores on the Maladaptive Behavior Domain of the Vineland Adaptive Behavior Scales of Children and Adolescents With Autism in a Placebo-Controlled Risperidone Trial and Open-Label Continuation Study 


\section{Maladaptive Behavior Domain of Vineland Adaptive Behavior Scales}

Table 2 shows the mean scores at baseline and the end of week 8 for part 1, part 2, and the total maladaptive behavior domain for the risperidone and placebo groups. The mean values for these measures are also shown for the end of the 16-week open-label phase (week 24 of the study). There was a significant interaction between treatment and time for each of these scores during the 8-week controlled phase of the study. There was no significant change in these measures over the 16-week continuation phase.

\section{Discussion}

In this controlled study, risperidone was more efficacious than placebo for improving scores on the subscales for sensory motor behaviors (subscale I), affectual reactions (subscale III), and sensory responses (subscale IV) and the overall score on the Ritvo-Freeman Real Life Rating Scale. Risperidone was not significantly better than placebo for improving the first two core symptom domains of autism, impaired social relatedness and language usage, as measured with subscales II (social relationship to people) and V (language) of the Ritvo-Freeman scale. These findings are similar to those of a double-blind, placebo-controlled study of risperidone for adults with autism and pervasive developmental disorder not otherwise specified (15). It is interesting that in the present study there was a nearly significant difference between risperidone and placebo in the social domain, as measured on subscale II (social relationship to people) $(\mathrm{p}<0.07)$, as well as on the social withdrawal subscale of the Aberrant Behavior Checklist (1). These results can be explained by the fact that reducing interfering tantrums, aggression, and self-injury allows the individual to be more available for social interaction. Alternatively, it may be that the rating instruments used to measure change in the social domain in this study were not sensitive enough. This dilemma points to the need for reliable and valid rating scales that are also sensitive to change in measures of social relatedness for use in treatment studies involving subjects with autism. Scales like the Social Responsiveness Scale $(25,26)$ may prove more useful for this purpose in future studies.

Restricted repetitive and stereotyped patterns of behavior, interests, and activities are the third core symptom domain of autism in DSM-IV. Although the types of repetitive phenomena demonstrated by persons with autism are different from those of individuals with OCD (21), the behaviors can cause significant impairment through time consumption and irritable reactions to interruptions $(3,27)$. In the current study, risperidone resulted in a significantly greater reduction of repetitive behavior than did placebo, as reflected in scores on the compulsion subscale of the modified Children's Yale-Brown Obsessive Compulsive Scale. This result is also in agreement with that of the placebo-controlled study of risperidone for adults with autism, in which the drug led to a significant reduction in Yale-Brown Obsessive Compulsive Scale scores over 12 weeks (15). Moreover, this decrease in repetitive behavior parallels the reduction observed on the stereotypy subscale of the Aberrant Behavior Checklist described in our initial report (1) and on subscale IV (sensory responses) of the Ritvo-Freeman Real Life Rating Scale in the current study, affirming the positive effects of risperidone for this symptom domain. This finding is not surprising in light of previous studies of haloperidol for children with autism, in whom significant reductions of stereotypic behavior were observed (28). Commenting on antipsychotic drug research in patients with mental retardation, Aman (29) noted that various types of stereotypic behavior were often the most sensitive measures of treatment effect. Both haloperidol and risperidone are potent dopamine $\mathrm{D}_{2}$ receptor antagonists, which have previously been shown to reduce refractory symptoms of OCD in adults when combined with ongoing therapy with serotonin reuptake inhibitors $(30,31)$.

Risperidone was also more efficacious than placebo for reducing scores on the total maladaptive behavior domain of the Vineland Adaptive Behavior Scales and on parts 1 and 2. Items in part 1 have been referred to as "minor maladaptive behaviors" and include symptoms found in attention deficit hyperactivity disorder, oppositional defiant disorder, and conduct disorder. A pilot placebo-controlled study of children and adolescents of normal intelligence with 
conduct disorder (32) and two large-scale double-blind, placebo-controlled studies of risperidone for children and adolescents with subaverage IQ and associated conduct problems $(33,34)$ previously showed the drug to be beneficial for these types of symptoms. Part 2 contains items considered "more serious maladaptive behaviors." Among them, self-injurious behavior and property destruction have been shown to improve with risperidone, as measured by change in the score on the irritability subscale of the Aberrant Behavior Checklist, as described in the initial report from this study (1).

As was observed with the primary outcome measures, the irritability subscale of the Aberrant Behavior Checklist and the CGI improvement scale (7), improvement in the secondary outcome measures described in this report was maintained during the 16-week continuation phase of the study. In addition, despite an additional 16 weeks of risperidone treatment, no statistically significant improvement was recorded in social relatedness or language usage, as measured by subscales II and V of the Ritvo-Freeman Real Life Rating Scale.

A limitation of the current study was the use of two modified rating instruments, the modified Ritvo-Freeman Real Life Rating Scale and Children's Yale-Brown Obsessive Compulsive Scale, for which reliability and validity have not yet been established. These modified instruments were used because there are no currently available instruments designed to measure change in these particular target symptom domains in this patient population. The psychometric properties of these modified instruments are currently being examined.

In summary, the results of this analysis of secondary measures indicate that 8 weeks of treatment with risperidone is not significantly different from placebo for the qualitative impairment in social interaction and communication that characterize autism, but repetitive and stereotyped patterns of behavior, interests, and activities did improve. This pattern of response was maintained with 16 additional weeks of risperidone therapy. Further studies aimed at identifying effective treatments for the core social and communicative impairment of autism are warranted.

\section{References}

1. Research Units on Pediatric Psychopharmacology Autism Network: Risperidone in children with autism and serious behavioral problems. N Engl J Med 2002; 347:314-321

2. McDougle CJ, Scahill L, McCracken JT, Aman MG, Tierney E, Arnold LE, Freeman BJ, Martin A, McGough JJ, Posey DJ, Riddle MA, Ritz L, Swiezy NB, Vitiello B, Volkmar FR, Votolato N, Walson P (Research Units on Pediatric Psychopharmacology [RUPP] Autism Network): Background and rationale for an initial controlled study of risperidone. Child Adolesc Psychiatr Clin N Am 2000; 9:201-224

3. Arnold LE, Aman MG, Martin A, Collier-Crespin A, Vitiello B, Tierney E, Asarnow R, Bell-Bradshaw F, Freeman BJ, Gates-Ulanet P, Klin A, McCracken JT, McDougle CJ, McGough JJ, Posey DJ, Scahill L, Swiezy NB, Ritz L, Volkmar F: Assessment in multisite randomized clinical trials of patients with autistic disorder: the Autism RUPP Network. J Autism Dev Disord 2000; 30:99- 111

4. Scahill L, McCracken J, McDougle CJ, Aman M, Arnold LE, Tierney E, Cronin P, Davies M, Ghuman J, Gonzalez N, Koenig K, Lindsay R, Martin A, McGough J, Posey DJ, Swiezy N, Volkmar F, Ritz L, Vitiello B: Methodological issues in designing a multisite trial of risperidone in children and adolescents with autism. $\mathrm{J}$ Child Adolesc Psychopharmacol 2001; 11:377-388

5. Aman MG, Singh NN, Stewart AW, Field CJ: The Aberrant Behavior Checklist: a behavior rating scale for the assessment of treatment effects. Am J Ment Defic 1985; 89:485-491

6. Guy W (ed): ECDEU Assessment Manual for Psychopharmacology: Publication ADM 76-338. Washington, DC, US Department of Health, Education, and Welfare, 1976, pp 218-222

7. Research Units on Pediatric Psychopharmacology Autism Network: Risperidone treatment of autistic disorder: longer term benefits and blinded discontinuation after six months. Am J Psychiatry (in press)

8. Freeman BJ, Ritvo ER, Yokota A, Ritvo A: A scale for rating symptoms of patients with the syndrome of autism in real life settings. J Am Acad Child Adolesc Psychiatry 1986; 25:130-136

9. Scahill L, Riddle MA, McSwiggin-Hardin M, Ort SI, King RA, Goodman WK, Cicchetti D, Leckman JF: Children's Yale-Brown Obsessive Compulsive Scale: reliability and validity. J Am Acad Child Adolesc Psychiatry 1997; 36:844-852 
10.Sparrow SS, Balla DA, Cicchetti DV: Vineland Adaptive Behavior Scales. Circle Pines, Minn, American Guidance Services, 1984

11.Arnold LE, Vitiello B, McDougle C, Scahill L, Shah B, Gonzalez NM, Chuang S, Davies M, Hollway J, Aman MG, Cronin P, Koenig K, Kohn AE, McMahon DJ, Tierney E: Parent-defined target symptoms respond to risperidone in RUPP Autism Study: customer approach to clinical trials. J Am Acad Child Adolesc Psychiatry 2003; 42:1443-1450

12.Lord C, Rutter M, Le Couteur A: Autism Diagnostic Interview— Revised: a revised version of a diagnostic interview for caregivers of individuals with possible pervasive developmental disorders. J Autism Dev Disord 1994; 24:659-685

13. Ritvo ER, Freeman BJ, Yuwiler A, Geller E, Schroth P, Yokota A, Mason-Brothers A, August GJ, Klykylo W, Leventhal B, Lewis K, Piggott L, Realmuto G, Stubbs EG, Umansky R: Fenfluramine treatment of autism: UCLA collaborative study of 81 patients at nine medical centers. Psychopharmacol Bull 1986; 22:133-140

14.McDougle CJ, Naylor ST, Cohen DJ, Volkmar FR, Heninger GR, Price LH: A double-blind, placebo-controlled study of fluvoxamine in adults with autistic disorder. Arch Gen Psychiatry 1996; 53:1001-1008

15.McDougle CJ, Holmes JP, Carlson DC, Pelton GH, Cohen DJ, Price LH: A double-blind, placebo-controlled study of risperidone in adults with autistic disorder and other pervasive developmental disorders. Arch Gen Psychiatry 1998; 55:633-641

16.Sanchez LE, Adams PB, Uysal S, Hallin A, Campbell M, Small AM: A comparison of live and videotape ratings: clomipramine and haloperidol in autism. Psychopharmacol Bull 1995; 31: 371-378

17.Goodman WK, Price LH, Rasmussen SA, Mazure C, Fleischmann RL, Hill CL, Heninger GR, Charney DS: The Yale-Brown Obsessive Compulsive Scale, I: development, use, and reliability. Arch Gen Psychiatry 1989; 46:1006-1011

18.Goodman WK, Price LH, Rasmussen SA, Mazure C, Delgado P, Heninger GR, Charney DS: The Yale-Brown Obsessive Compulsive Scale, II: validity. Arch Gen Psychiatry 1989; 46:1012-1016

19.Scahill L, Kano Y, King RA, Carlson A, Peller A, LeBrun U, Rosario-Campos MC, Leckman JF: Influence of age and tic disorders on obsessive-compulsive disorder in a pediatric sample. J Child Adolesc Psychopharmacol 2003; 13(suppl 1):7-18

20.Volkmar FR, Klin A, Cohen DJ: Diagnosis and classification of autism and related conditions: consensus and issues, in Handbook of Autism and Pervasive Developmental Disorders, 3rd ed. Edited by Cohen DJ, Volkmar FR. New York, John Wiley \& Sons, 1997, pp 5-40

21.McDougle CJ, Kresch LE, Goodman WK, Naylor ST, Volkmar FR, Cohen DJ, Price LH: A case-controlled study of repetitive thoughts and behavior in adults with autistic disorder and obsessive-compulsive disorder. Am J Psychiatry 1995; 152:772-777

22. McDougle CJ, Holmes JP, Bronson MR, Anderson GM, Volkmar FR, Price LH, Cohen DJ: Risperidone treatment of children and adolescents with pervasive developmental disorders: a prospective open-label study. J Am Acad Child Adolesc Psychiatry 1997; 36:685-693

23. Gibbons RD, Hedeker D, Elkin I, Waternaux C, Kraemer HC, Greenhouse JB, Shea MT, Imber SD, Sotsky SM, Watkins JT: Some conceptual and statistical issues in analysis of longitudinal psychiatric data: application to the NIMH Treatment of Depression Collaborative Research Program dataset. Arch Gen Psychiatry 1993; 50:739-750

24.Littell RC, Miliken GA, Stroup WW, Wolfinger RD: SAS System for Mixed Models. Cary, NC, SAS Institute, 1996

25.Constantino JN: The Social Responsiveness Scale. Los Angeles, Western Psychological Services, 2002

26. Constantino JN, Davis SA, Todd RD, Schindler MK, Gross MM, Brophy SL, Metzger LM, Shoushtari CS, Splinter R, Reich W: Validation of a brief quantitative measure of autistic traits: comparison of the Social Responsiveness Scale with the Autism Diagnostic Interview—Revised. J Autism Dev Disord 2003; 33: 427-433

27. McDougle CJ, Kresch LE, Posey DJ: Repetitive thoughts and behavior in pervasive developmental disorders: treatment with serotonin reuptake inhibitors. J Autism Dev Disord 2000; 30: 425-433

28.Campbell M, Anderson L, Meier M, Cohen I, Small A, Samit C, Sachar E: A comparison of haloperidol and behavior therapy and their interaction in autistic children. J Am Acad Child Psychiatry 1978; 17:640-655

29. Aman MG: Recent studies in psychopharmacology in mental retardation. Int Rev Res Ment Retard 1997; 21:113-146

30.McDougle CJ, Goodman WK, Leckman JF, Lee NC, Heninger GR, Price LH: Haloperidol addition in 
fluvoxamine-refractory obsessive compulsive disorder: a double-blind, placebo-controlled study in patients with and without tics. Arch Gen Psychiatry 1994; 51:302-308

31.McDougle CJ, Epperson CN, Pelton GH, Wasylink S, Price LH: A double-blind, placebo-controlled study of risperidone addition in serotonin reuptake inhibitor-refractory obsessive-compulsive disorder. Arch Gen Psychiatry 2000; 57:794-801

32.Findling RL, McNamara NK, Branicky LA, Schluchter MD, Lemon E, Blumer JL: A double-blind pilot study of risperidone in the treatment of conduct disorder. J Am Acad Child Adolesc Psychiatry 2000; 39:509-516

33. Aman MG, De Smedt G, Derivan A, Lyons B, Findling RL (Risperidone Disruptive Behavior Study Group): Double-blind, placebo-controlled study of risperidone for the treatment of disruptive behaviors in children with subaverage intelligence. Am J Psychiatry 2002; 159:1337-1346

34. Snyder R, Turgay A, Aman M, Binder C, Fisman S, Carroll A (Risperidone Conduct Study Group): Effects of risperidone on conduct and disruptive behavior disorders in children with subaverage IQs. J Am Acad Child Adolesc Psychiatry 2002; 41:1026- 1036. 